\title{
HAEMOGLOBINOPATHIES IN IMMIGRANT
}

\section{FAMILIES}

\author{
M. J. BEARD, M.R.C.P. (Edin.), M.C. Path. \\ Senior Registrar, Department of Haematology. \\ A. Gordon Signy, M.B., S.C. Path. \\ Consultant Haematologist.
}

Group Laboratory

St. Stephen's Hospital, London, S.W.10.

MANY of the haemoglobinopathies occur almost exclusively in the negro races and however these patients present clinically, the presence of an abnormal haemoglobin can usually be quickly confirmed or excluded. When these conditions occur in other racial groups such as Indians, Asians and in the Mediterranean countries, then their presence may not be suspected so quickly and thus lead to confusion and unnecessary treatment.

A knowledge of the geographical distribution of the haemoglobinopathies is a useful guide to the probable abnormality which may exist in the individual patient. The main facts are well known but a few points are worth re-emphasizing.

Haemoglobin $S$ shows a main incidence in people of African stock but it does also occur in some areas of Southern India. Thalassaemia was originally thought to be concentrated in the Mediterranean but is now known to extend in a broad belt eastwards and to have a high incidence in many Asian countries. Thalassaemia is rare in many parts of Africa, $\beta$-thalassaemia having been estimated at 1 in 2,000 in Nigeria (Watson Williams, 1965).

The wide distribution of these harmful genes has led to investigations into possible balancing favourable effects. It is now generally accepted that the sickle cell trait protects the bearer against the lethal effects of $\boldsymbol{P}$. falciparum malaria, and there is some evidence that the presence of haemoglobin C trait may act in a similar way.

It has been our experience that many of the patients we see have, surprisingly, not been diagnosed before their arrival in this country, but this will obviously become less common as medical care becomes more widely available. The clinical difficulties are numerous and one of the most important is the difficulty of assessing anaemia in the darker skinned races. As the case reports show, many conditions may be simulated and crises accompanied by abdominal or bone pain may be particularly worrying if the underlying haemoglobinopathy has not been previously diagnosed.

The particular association of salmonellaw osteomyelitis with sickle cell anaemia has beet well documented (Van Oye, 1960).

\section{Structure and Inheritance of Haemoglobin}

Haemoglobin is a chromoprotein with probable molecular weight of 64,458. Thळ three dimensional structure of its 4 polypeptidê chains and its 4 haem groups has been exten? sively studied. Each $\alpha$ chain has been found to contain 141 amino-acid residues and each $\beta$ chain 146. These chains are folded and coilecf in a complex arrangement to each other witlo cross-binding hydrogen bonds to incresses stability. The haem moiety is thought to $\$$ near the surface of the molecule with its i iono forming a bond with the amino-acid histidme of its corresponding polypeptide chain. The exact mechanism whereby this complexw structure enables haemoglobin to undertake itso oxygen-carrying functions remains unknown.

In addition to haemoglobin $A$, two othe $\vec{P}$ haemoglobins occur in normal adults, foetaP haemoglobin with $2 \alpha$ chains and $2 \gamma$ chain and haemoglobin $\mathrm{A}_{2}$ with $2 \gamma$ chains and 2 \& chains. Both $\gamma$ and $\delta$ chains show close simio larities to $\beta$ chains in their amino aciof:

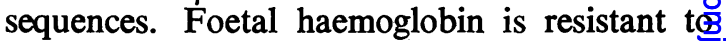
alkali and in the adult less than $2 \%$ is presents the exact amount recorded depending upon the technique used. Haemoglobin $\mathrm{A}_{2}$ shows a meab value of $2.5 \%$ when the most accurate tech? niques are employed. There is evidence that the level of foetal haemoglobin in the adult is: under independent control and the familias condition of hereditary persistence of high foetail haemoglobin supports this. In this condition there is no anaemia and no change in red ceff morphology, but a considerable increase in the $\%$ of foetal haemoglobin.

Most abnormal haemoglobins are characs terised by the substitution of just one aminoacid in either the $\alpha$ or the $\beta$ chain. Most commonly the substitution occurs in the 
chain whereas $\alpha$ chain substitution is less common. The effects of this amino-acid replacement seems to depend mainly on the nature of the new amino-acid and its position in the polypeptide chain. Thus the replacement of just 2 out of 574 amino-acids may lead on the one hand to severe disease with a high mortality and on the other to no detectable clinical abnormality. The overall changes in the electrical charge of the molecule that occur as a result of its altered amino-acid content are particularly important.

The common abnormal haemoglobins S, C, E and $D$ are all inherited as Mendelian dominants. The severity of illness associated with the homozygous state varies but heterozygote are nearly always symptom free. However, in thalassaemia a heterozygote may show a mild or moderate anaemia and some studies have suggested that the sickle cell trait may not be so benign as it is usually assumed to be. In the sickle trait, haematuria, splenic infarction and abscess, hip joint changes and osteomyelitis have all been recorded. The underlying defects and mode of inheritance of thalassaemia are extremely complex and an explanation based on multiple genetic defects, which are usually inherited together but may be transmitted independently, seems best able to explain the varied clinical picture. In thalassaemia, no abnormal haemoglobin has been identified and the anaemia is thought to result from a partial or complete suppression of one of the pairs of polypeptide chains of haemoglobin A. The $\beta$ chain is more commonly involved than the $\alpha$ chain and when demonstrated the cases are referred to as either $\alpha$ or $\beta$ thalassaemia.

The production of $\alpha$ and $\beta$ chains is under independent genetic control and each individual inherits genes controlling the nature of these chains from both parents. The inheritance of an $\alpha$ chain defect from one parent with a $\beta$ chain defect from the other, could then lead to the presence of up to four haemoglobins in the one individual. Cases illustrating this have been recorded (Raper, Gammack, Huenns and Shooter, 1960; Hall-Craggs, Marsen, Raper, Lehmann and Beale, 1964) and they provide excellent support for the present genetic theory of haemoglobin production. It is also interesting to note that the polypeptide chains always occur in identical pairs and mixed molecules such as $\alpha \mathrm{A} \alpha \mathrm{A} / \beta \mathrm{A} \beta \mathrm{S}$ do not occur. It has thus been postulated that biosynthesis of these chains occurs in pairs or that identical chains are paired before they contact unlike chains (Itano and Robinson, 1959).

\section{Effects on the Blood}

In the homozygous state the effects of an amino-acid substitution in the polypeptide chains vary greatly. Almost always some morphological change is seen in the red cells, target cells being seen in many instances. The altered physical properties of haemoglobin $S$ provide a basis for the clinical picture in diseases associated with this abnormal haemoglobin. Oxyhaemoglobin $\mathrm{A}$ and $\mathrm{S}$ have the same solubility but whereas the solubility of haemoglobin A falls by half on deoxygenation, the solubility of haemoglobin $S$ falls by 50 times. Thus when deoxygenated, and also when the $\mathrm{pH}$ falls, haemoglobin $\mathrm{S}$ forms a semisolid gel within the red cell producing the characteristic sickle or holly-leaf deformity. The ease with which this gel is formed is related to the concentration of haemoglobin $\mathrm{S}$ in the cell. The concentration of $\mathrm{S}$ is $80-100 \%$ in sickle cell anaemia, $50-60 \%$ in haemoglobin S-C disease and $20-40 \%$ in sickle trait and this forms the basis for their differing clinical severity. Deoxygenation or fall in $\mathrm{pH}$ causes sickling which results in increased blood viscosity. Vascular stasis leads to the establishment of a vicious circle ending in thrombosis and infarction.

Most of the abnormal haemoglobins in the homozygote produce a haemolytic state of variable severity but substitution in the histidyl amino-acid linking haem to the polypeptide chain, may affect the oxygen carrying ability of the molecule and this forms one type of inherited methaemoglobinaemia. In thalassaemia variable suppression of haemoglobin A occurs and deformed, hypochromic red cells are produced, the anaemia being a combination of defective production and shortened red cell life.

\section{Screening Tests}

Examination of the blood film will almost always reveal some abnormalities but cannot be relied upon to exclude a haemoglobinopathy. Target cells are common and are seen in greatest numbers in haemoglobin $\mathbf{C}$ disease. Sickle cells may be seen on the stained film and if they are, this nearly always indicates either sickle cell anaemia, or the S-C; S-thalassaemia combinations. The hypochromasia of thalassaemia is easily confused with iron deficiency but in iron deficiency the MCHC is more markedly reduced whereas in 


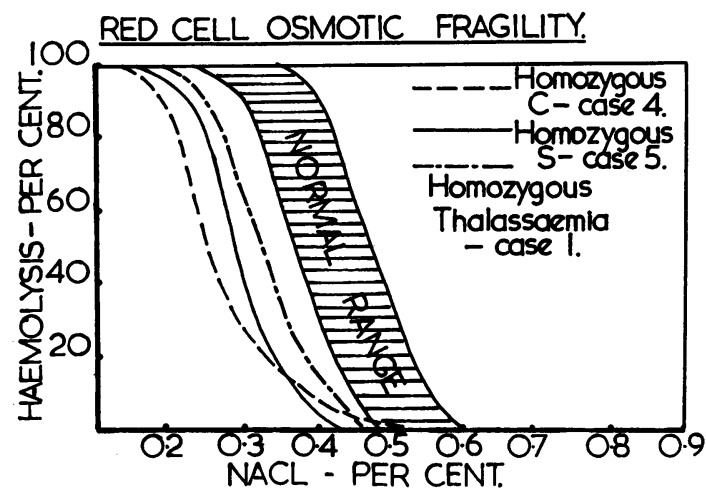

FIG. 1.-Fragility curves.

thalassaemia target cells, punctate basophilia, nucleated red cells, and polychromasia may also be seen. An increased resistance to hypntonic saline (i.e. shift to left in fragility curve) (Fig. 1) is frequently found, but again is of little use as a screening procedure. Except perhaps in thalassaemia, haemoglobin $S$ can be detected by the in vitro sickling test.

Electrophoresis forms the basis for detection of abnormal haemoglobins in the hospital laboratory. Many technical variations have been employed, but the use of cellulose acetate as a quick screening method together with starchgel electrophoresis for more critical studies is a useful combination. (Fig. 2). Starch-gel electrophoresis is probably the best method of separating haemoglobin $A_{2}$, and this is of great importance in the diagnosis of thalassaemia carriers. Using a starch gel the amount of haemoglobin $\mathrm{A}_{2}$ in normals is about $2.5 \%$, whereas in over $90 \%$ of thalassaemia carriers, values of about $5 \%$ are found. It is important to remember that haemoglobin electrophoresis may have to be carried out using different buffers and at differing $\mathrm{pH}$ before some of the abnormal haemoglobins can be detected.

Alkali resistant haemoglobin may also be estimated by a number of techniques. Singer's technique (Singer, Chernoff and Singer, 1951) is most commonly used but is unreliable in detecting values below $2 \%$. The fact that only about $50 \%$ of thalassaemia carriers will show a raised foetal haemoglobin emphasises the greater value of haemoglobin $A_{2}$ estimation in this context.

More recently extremely interesting results have been obtained from techniques which can demonstrate the distribution of some normal and abnormal haemoglobins in the red cell population. An example of this is the technique of Betke and Kleihauer (1958) for foetal haemoglobin. This has demonstrated that ing hereditary persistence of high foetal haemo $\mathbb{Q}$ globin, haemoglobin $F$ is evenly distributed in: all red cells, whereas in sickle cell anaemia $=$ foetal haemoglobin is present in only a minority of the red cells and in amounts which vary from cell to cell. The application of this it the precise diagnosis of sickle cell anaemia iक्ष discussed by Apthorp, Measday and Lehmanis (1963).

Screening tests have been applied to large hospital populations and are being used in clinical anaemias with surprising results. Thusu the identification of thalassaemia in a famils of pure Scottish ancestry (Buchanan, Kinlock Hutchinson, Pinkerton and Cassidy, 1963) ant in the South of England (Roberts, 1963) demonstrate the value of these techniques. It is strongly recommended that regular screening tests for abnormal haemoglobin should be used in the increased coloured population of the country-particularly as part of the routine? testing of pregnant women.

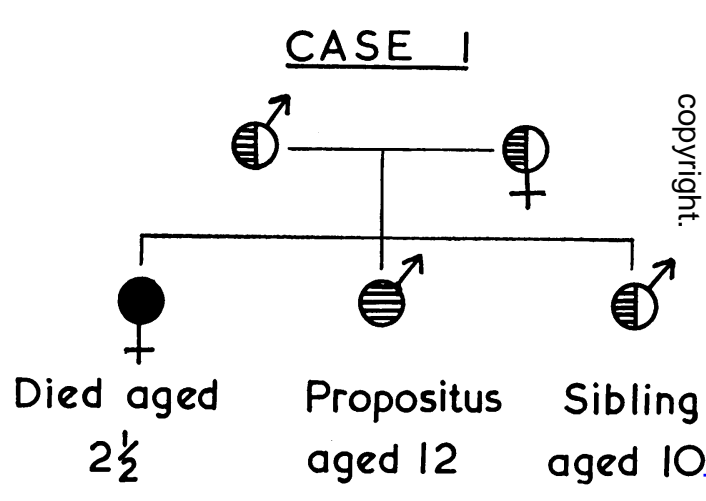

Case no. 1. Thalassaemia Major

The child was first seen at the age of three years when he was found to be grossly anaemic.

Family History: His parents are Cypriots. They had lost one daughter at the age of $2 \frac{1}{2}$ with thalassaemia major and recurrent severe haemolytic crises. The second child, a boy, is the patient here described and they also have a third child, a boy? who only has the trait and is in perfectly good health The father and the third child have no haemoglobin $F$, but raised $A_{2}$, and the mother has both haemo
globin $F(4.5 \%)$ and $A_{2}$ raised. (See chart).

On examination the spleen was $5 \mathrm{~cm}$. below the costal margin. His haemoglobin was $3.6 \mathrm{~g} . / 100 \mathrm{ml}$. MCHC $30 \%$, the blood film was hypochromic with moderate numbers of target cells. Reticulocytes $4 \%$ o Haemoglobin F level $70 \%$. No abnormal haemoglobins present, and the haemoglobin $A_{2}$ content was not increased. Blood from his father showed a fewe target cells but a normal fragility and no hypo? chromasia. Haemoglobin F was not detected, buto the haemoglobin $A_{2}$ raised. Blood from his motheo was hypochromic with an abnormal red cell fragility Haemoglobin $\mathbf{F} 4.5 \%$, haemoglobin $\mathbf{A}_{2}$ raised. 


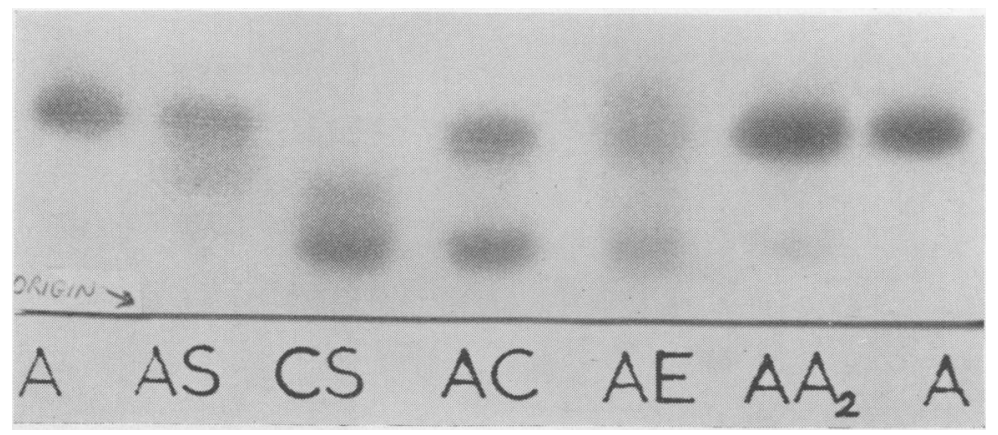

FIG. 2.-Abnormal haemoglobins. Starch gel electrophoresis.

This child is now 12 years old and has required 160 pints of blood during the past 9 years with increasing frequency, in an attempt to maintain haemoglobin level at $7 \mathrm{~g} . / 100 \mathrm{ml}$., and transfusion has to be instituted when it falls to below $4 \mathrm{~g} . / 100 \mathrm{ml}$. $\mathrm{He}$ leads a moderately normal life between, but is very resentful of the regular hospitalisation for blood transfusion. Iron chelating agents are being used in an attempt to minimise the inevitable iron overload. His illness has caused many difficulties and much distress for his family. In an attempt to reduce his transfusion requirements the advisability of splenectomy was now considered, his spleen being $8 \mathrm{~cm}$. below the costal margin. It was performed on 29.7.65. Haemolysis was demonstrated by radioactive chromium studies. The red cell half life of a mixed population of red cells (chromium 51) was 19 days with some excess accumulation of activity over the splenic area before the operation.

Comment: The suffering of both patient and parents that occurs in the clinically severe haemoglobinopathies is shown in this case. The advisability of splenectomy should be considered in every case of thalassaemia with a high transfusion requirement. The problem of iron overload should be tackled as early as possible, the easiest way being to incorporate a chelating agent in the transfused blood.

Case no. 2. Thalassaemia Trait

This lady was 73 when she was admitted for re-evaluation in 1964. She was of mixed Irish and Pakistan extraction. She had had a hypochromic anaemia for 20 years which had not responded to iron therapy. For the past 7 years she had been troubled by recurrent urinary tract infections.

A diagnosis of thalassaemia trait was suggested by the following findings:

Haemoglobin 9.0 g. $/ 100 \mathrm{ml}$. MCHC $31 \%$. Reticulocytes $2-3 \%$. Red cells showed fairly marked hypochromasia with moderate punctate basophilia. The degree of hypochromasia was felt to be too marked to be explained by chronic infection alone. Red cells showed an increased resistance to hypotonic saline. Serum iron normal. Bone marrow showed an erythroid hyperplasia and an increase in stainable iron, but only a slight increase in sideroblasts and no ring sideroblasts were present. Haemoglobin $F$. was not detected but haemoglobin $\mathbf{A}_{2}$ level raised to $5 \%$.

Despite her recurrent urinary infections, her blood urea remains normal. Her urinary infection is now being treated with long term antibiotics. The family have so far resisted attempts to confirm the diagnosis beyond all doubt.

\section{Case no. 3. Thalassaemia Carrier}

This Greek Cypriot lady was 32 when seen in July 1964. She was six months pregnant and had had a small ante partum haemorrhage. She was anaemic with a haemoglobin of $8.8 \mathrm{~g}$. $/ 100 \mathrm{ml}$. Reticulocytes $3 \%$, MCHC $30 \%$. The blood film showing moderate hypochromasia with fairly marked punctate basophilia. The haemoglobin remained unchanged and the reticulocytes slightly raised despite adequate oral and parenteral iron therapy followed by folic acid. The possibility of thalassaemia was then considered and although the foetal haemoglobin was not raised, the haemoglobin $\mathbf{A}_{2}$ fraction was elevated. She eventually required caesarian section for placentapraevia. Six weeks after delivery her haemoglobin was $11.0 \mathrm{~g} . / 100 \mathrm{ml}$.

Her past obstetric history showed pregnancies in 1955 and 1957 both supervised at a London teaching hospital. On each occasion the haemoglobin was recorded as $60 \%$ and the blood film hypochromic; oral and parenteral iron were given but no record of the response made.

The diagnosis of thalassaemia carrier is being established by family studies.

Comment: The difficulty of diagnosing thalassaemia carriers is well recognised. The much greater value of haemoglobin $\mathbf{A}_{2}$ estimation as opposed to haemoglobin $F$. estimation as a screening procedure is illustrated here. The precipitation of anaemia by the pregnancy and the return of the haemoglobin to near normal values after delivery are also worth noting.

In Case 2, the patient has taken large quantities of iron unnecessarily for about 20 years. It is likely also that the degree of anaemia has been made more severe by the constant urinary tract infection.

These two cases illustrate the variable haemoglobin level that may be found in the thalassaemia trait and its fluctuation in association with conditions that may put stress on the bone marrow.

The near impossibility of adequate family studies in an immigrant community makes full investigation of this aspect of haemoglobinopathies difficult in this country. The difficulty of establishing the diagnosis of the thalassaemia trait makes family studies more important than in some of the other more easily diagnosed haemoglobinopathies.

\section{Case no. 4. Haemoglobin IC Disease}

This 26 years old West Indian lady attended the antenatal clinic in 1962 when she was 5 months pregnant. She was symptom-free and said she had been in good health all her life. She had had three previous pregnancies in Barbados and all had been apparently normal. 


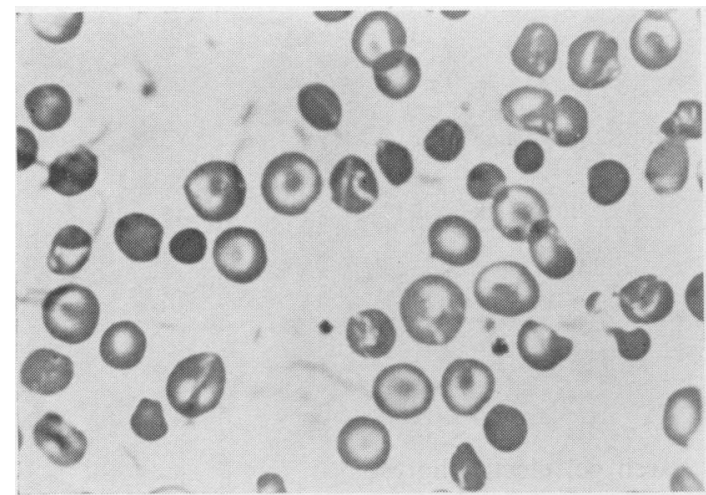

FIG. 3.-Homozygous C disease. Target cells with microspherocytes.

On examination her spleen was just palpable and after delivery it was felt $3 \mathrm{~cm}$. below the costal margin.

The haemoglobin varied between 8 and $10 \mathrm{~g} . / 100$ $\mathrm{ml}$. and the reticulocytes were $4 \%$. The blood film showed many target cells and moderate numbers of microspherocytes. (Fig. 3). Haemoglobin electrophoresis showed haemoglobin $\mathrm{C}$ only, foetal haemoglobin not being detected. No family studies were possible.

Comment: This patient was homozygous for haemoglobin $\mathrm{C}$ and shows how mild this particular defect may be clinically.

Case no. 5. Sickle Cell Anaemia

This lady was 31 when she presented in 1963. She came from Sierra Leone. She complained of recurrent ulceration of the left leg since 1956. There was a past history of typhoid in 1955 and in 1956 she had a long illness with much pain in the left leg. The ulceration developed subsequent to this latter illness. Since 1956 she had been in good general health.

On examination she was jaundiced and anaemic. The ulcer was about $3 \mathrm{~cm}$. in diameter, surrounded by scar tissue and situated over the medial aspect of the left tibia just above the ankle joint. X-ray examination of the left leg showed an old osteomyelitis of the fibula mainly of its middle third with cross union between it and the tibia. (Fig. 4). There was thus no obvious direct connection between the skin ulceration and the old osteomyelitis. A swab from the ulcer grew staphylococcus aureus sensitive to penicillin.

The spleen was just palpable. A loud ejection systolic murmur was heard over the entire precordium. Chest X-ray revealed marked cardiac enlargement.

The haemoglobin was $9.0 \mathrm{~g} . / 100 \mathrm{ml}$. and the reticulocytes $11 \%$. The blood film showed fair numbers of sickle cells and occasional target cells. (Fig. 5). Haemoglobin electrophoresis revealed only haemoglobin $\mathrm{S}$; alkali denaturation gave a foetal haemoglobin of $3.9 \%$.

The ulcer healed with bed rest and she was discharged symptom free. The cardiac enlargement and murmur were thought to be an example of the cardiac complications which may occur in sickle cell anaemia.

She was seen again in 1964 when she was 4 months pregnant. Her haemoglobin now gradually fell to 7.5 g. $/ 100 \mathrm{ml}$. and the reticulocytes showed a tendency

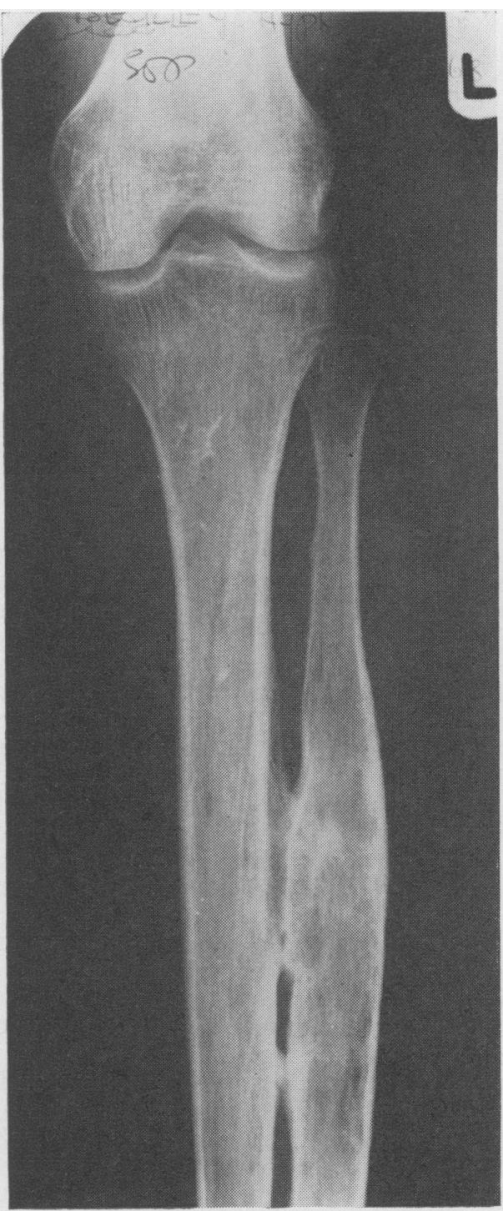

Fig. 4.-Homozygous $S$ disease. X-ray osteomyelitis Case 5

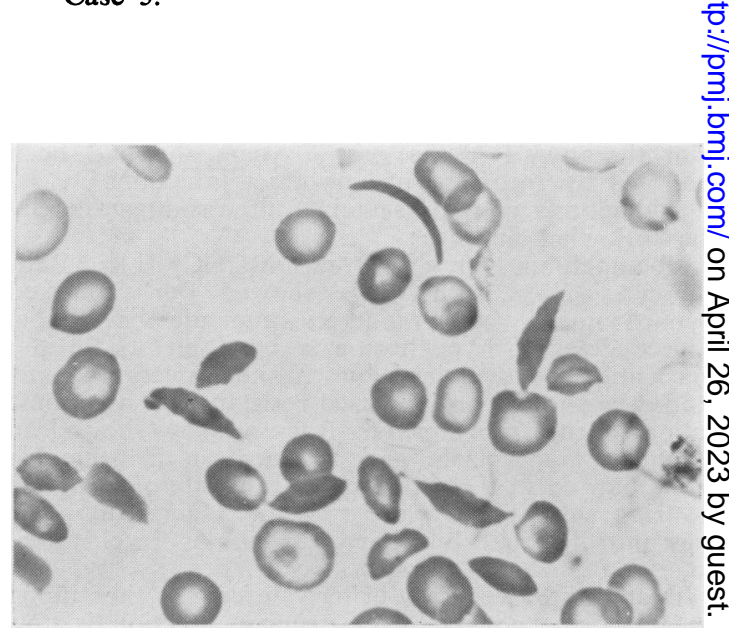

FIG. 5.-Homozygous $S$ disease. Sickle cells with larger cells. Case 5. 
to rise averaging $25 \%$ in late pregnancy. During pregnancy she was easily tired and required several admissions to hospital for rest. She was digitalised when 8 months pregnant as there had been evidence of congestive cardiac failure. For the last 4 months of pregnancy she had been taking $20 \mathrm{mg}$. of folic acid daily. Delivery and subsequent progress of mother and child were normal. Three months after delivery she returned to Africa. During and after the pregnancy the spleen could not now be felt.

Comment: This case is interesting for the mild clinical state despite the fairly severe haemolytic anaemia. The history suggests that this may have been an example of salmonellae osteomyelitis although $S$. typhi is only very rarely isolated from these cases. Salmonellae of the food poisoning type (i.e. typhimurium) are usually involved and emphasize how dangerous a relatively benign enteritis may be for patients with sickle cell disease. The complete absence of any crises is also an unusual feature.

The possible decrease in spleen size may be observer error. However in America the spleen is rarely reported as being palpable in sickle cell anaemia and this contrasts with the fairly frequent splenomegaly reported in $50-80 \%$ of cases seen in Africa. There is evidence that spleen size in this condition may be partly related to co-existing malarial infection, or to repeated infarctions.

\section{Case no. 6. Sickle Cell Anaemia}

This patient also came from Sierra Leone and first presented in 1951 at the age of 26 . He complained of intermittent yellowness of the eyes for 12 years. There was a past history of malaria as a child. His haemoglobin was $7.4 \mathrm{~g} . / 100 \mathrm{ml}$., reticulocytes $19 \%$, and many sickle cells were seen on the blood film. The bilirubin varied between 2.6 and $9.0 \mathrm{mg} . / 100 \mathrm{ml}$. Haemoglobin electrophoresis established the diagnosis of homozygous sickle cell disease, the haemoglobin F. level not being increased.

Over the next 6 years his clinical course was extremely episodic, he remained anaemic and jaundiced throughout but his degree of jaundice fluctuated. $\mathrm{He}$ had several crises. A typical one occurred in 1957 when he was admitted to hospital with a 4-day history of pain and swelling of the interphalangeal joints and the left ankle, together with fever and headache. On examination he was jaundiced and anaemic. Temperature was $103^{\circ} \mathrm{F}$. Slightly enlarged glands were present in axillae and groins. These symptoms and signs gradually subsided over the following two weeks. In other crises unexplained abdominal pain was a prominent feature.

In 1953 priapism associated with thrombosis of the dorsal vein of the penis was troublesome. For a perid of about 3 weeks late in 1953 an ulcer $5 \mathrm{~cm}$. in diameter appeared just above the right ankle, but this cleared spontaneously. An X-ray in 1957 showed avascular necrosis of the left femoral head. He returned to Africa in December 1957. Family studies were not possible.

Comment: Many features of sickle cell disease are shown by this patient. The recurrent crises with joint, bone, and abdominal pain, priapism, avascular necrosis of the femoral head, and leg ulceration were all seen at some stage.

\section{Case no. 7. Haemoglobin S-C Disease}

The patient was a male aged 48 from the West Indies. When he presented in December 1964, he had had pain in the right side of the chest with a persistent cough and shortness of breath for one week. He gave a past medical history of pneumonia in 1954 and June 1964, but apart from this he had been in good health all his life. Hb. $12.0 \mathrm{g.} \%$, retics $5 \%$. Electrophoresis shows S-C. haemoglobin pattern.

No firm diagnosis was made, but he was thought to have either pneumonia or pulmonary infarction and the X-ray shadowing gradually returned to normal. Four days after admission he complained of pain in the right calf and this was due to deep vein thrombosis.

Apart from some residual pain in the right leg he is now in good health.

Comment: This patient has been in good health almost all his life, with nothing to suggest a crisis at any time. It has been suggested that there may be an increased incidence of venous thrombosis and pulmonary embolism in haemoglobin S-C disease but this remains unproven. It seems likely that in both this case and in case 8, pulmonary infarction occurred. Case no. 8

This lady from Barbados was 39 when she attended the antenatal clinic in 1963. She was 11 weeks pregnant and gave a past history of a normal pregnancy in 1947, but miscarriages at 22 and 24 weeks in 1961 and 1962. In 1962 she had toxaemia and a right lower lobe pneumonia which was resistant to antibiotics but after the spontaneous delivery of a macerated foetus she rapidly returned to normal health. During these admissions the haemoglobin was 11 to $12 \mathrm{~g} . / 100 \mathrm{ml}$., the reticulocytes between 2 and $11 \%$. Haemoglobin electrophoresis showed S. and C. haemoglobins, only foetal haemoglobin not being detected.

The present pregnancy proceeded normally until the onset of vaginal bleeding at 24 weeks and when she was admitted to hospital it was found she also had a left lower lobe pneumonia and a urinary infection. Again the chest infection proved resistant to antibiotics and after admission she had an episode of haemoptysis. After several weeks she was delivered of a macerated foetus with subsequent clinical improvement. To prevent further pregnancies, bilateral salpingectomy was performed.

Comment: This patient with S-C disease suffered three successive miscarriages all at about six months, althought some years previously she had had a normal pregnancy. There were no demonstrable antibodies present in her blood. The usual resistance of the chest condition to antibiotics, together with the haemoptysis and radiological appearances made pulmonary infarction the most likely diagnosis, although unlike Case 7 no evidence of peripheral venous thrombosis could be found. The association of $\mathrm{S}-\mathrm{C}$ disease with an increased incidence of abortion is well recognised. (Curtis, 1959).

\section{Prognosis}

The prognosis of these conditions varies enormously. In many the exact prognosis is difficult to assess. The general level of health and nutrition and the amount of medical care available will vary from country to country, and these factors will significantly affect the prognosis. This may partly or wholly explain the poorer prognosis for sickle cell anaemia in Africa when compared with the Southern States of America. There is good reason to hope that with the improvement in living standards and medical care the overall prognosis will improve. 
Sickle cell anaemia, thalassaemia and the various combinations of $S$ with other defects as in S-C disease and S-thalassaemia, make up nearly all the severely affected patients. It is impossible to generalise concerning the prognosis in the thalassaemias. In homozygotes many cases are severely affected even leading to death in utero or hydrops foetalis. However, cases which are clinically mild also occur. Fessas (1963) discussed the very complicated problem of classification of thalassaemia and its relation to the prognosis in the individual case.

Sickle cell anaemia has a poor prognosis, many patients dying in the first decade and this is reflected in statistics from Leopoldville, where out of 1,879 sickle cell anaemias only 15 were over 18 years of age (Vandepitte and Stijns, 1963).

Although the prognosis in haemoglobin S-C disease is better than in sickle cell anaemia, crises may occur and pregnancy is thought to be particularly hazardous. The maternal mortality in two large series was $21.6 \%$ (Eisenstein, Posner and Friedman, 1956) and $10 \%$ (Fullerton, Hendrickse and WatsonWilliams, 1963). Improvements in management introduced by Fullerton and others considerably lowered their mortality rate in the later part of their series.

\section{Prevention}

The theoretical possibility of prevention of sickle cell anaemia and other homozygous states by controlling marriage between affected carriers is generally held to be impracticable. If the main benefit conferred by the sickle gene is a degree of protection against malaria, then with the control of malaria in many parts of the world, the incidence of the sickle gene will gradually fall. However, it may be important to the individual to know whether he carries any of these abnormalities as he may choose to avoid a marriage which might result in the birth of severely affected children, but this is no more likely than the avoidance of an $\mathrm{Rh}$. positive partner by a Rh. negative woman!

Modification of the disease in the neonate by marrow infusions from normal donors is an attractive possibility. The survival of only a few cells capable of producing haemoglobin A might significantly influence the development of severe sickle cell anaemia or thalassaemia major. Many difficulties must be overcome before this becomes a reality. Relatively little is known about the immunologic reactivity of the neonate and furthermore the precise diagnosis of the homozygous state is often extremely difficult at birth.

\section{Treatment}

There is much that can be done to prolon life and reduce suffering and often an unduly pessimistic view is taken of therapy. The use of transfusions in correcting anaemia will varf from patient to patient, but many do not require blood unless the haemoglobin falls below g./100 ml. Exchange transfusions have bee: used in treating crises occurring in pregnanco complicated by haemoglobin S-C disease. Foliz acid therapy has been shown to increase the haemoglobin levels in an appreciable number of patients with sickle cell anaemia in Africa It has also been used in the treatment of crises in which depletion of folic acid may occur, and in the common megaloblastic anaemia of pregnancy in haemoglobin S-C disease. In fact should pregnancy occur in any woman with moderate or severe haemoglobinopathy, folio acid should be given prophylactically as earl $\$$ as possible in the pregnancy. There is evidence that in Africa, physical immaturity in patients with severe disease may be considerably improved by long term folic acid therapy. Th8

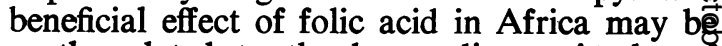
partly related to the lower dietary intake of folic acid in many of the population.

Crises require symptomatic treatment, bukigh addition antibiotics and folic acid should कै given. Heparin has been used in sickle ces anaemia and haemoglobin S-C disease and was thought to be beneficial particularly in criseg associated with bone pain. Although the duration of the pain was unchanged, the therap was thought to have reduced the death rate (Fullerton and others, 1963). Apthorp and others (1963) advocate the use of magnesiun sulphate and sodium bicarbonate in doses sufficient to keep the urine alkaline and cons sider that this reduces the frequency and severit of crises in sickle cell anaemia. The unpredic table nature and frequency of these crises which may occur in most chronic haemolytie states, makes it very difficult however to assess the value of therapeutic agents. It has been established that anaesthesia is dangerous is sickle cell anaemia, but in the sickle cell trait its effects have still to be assessed. In any patient with sickle cell anaemia, sickle cell traits or haemoglobin S combined with some otherv abnormality, the use of tourniquets at any time must be avoided.

Splenectomy may have to be considered if thalassaemia (see Case 1) and careful pre ${ }^{\circ}$ operative assessment is essential (Smitho Erlandson, Stern and Schulman, 1960). Subô? stantial reduction in transfusion requirements 
have been recorded after splenectomy in properly selected cases, but against this must be balanced the risks of the operation and the possible subsequent death from overwhelming sepsis. Several such cases have been recorded mostly some appreciable time after the operation, but the exact risk is difficult to assess.

Chelating agents should prove valuable in preventing the iron overload in those cases requiring frequent transfusions. It is essential to start this treatment early rather than wait until a state of iron overload exists.

Finally it is important to stress the need to maintain good general health and an adequate dietary intake. There is good evidence that increased amounts of folic acid are required particularly by the more severely affected patients and the ease with which they may become folic acid deficient will obviously be related to their dietary intake.

\section{Glucose-6-Phosphate Dehydrogenase Deficiency}

Gluc o s e - 6-phosphate dehydrogenase (G.6.P.D.) deficiency has been estimated to affect roughly 100 million people. Its irregular geographical distribution closely parallels both the frequency of the sickle cell gene and the distribution of falciparum malaria. The deficiency can be subdivided into two main groups, the "negro" and the "non-negro". The negro type has an incidence of around $10 \%$ in the American negro and probably about the same level in the West Indian islands. In West Africa and the Congo the incidence averages about $20 \%$ although much lower frequencies are seen in the South African Bantu and it is virtually absent among Ethiopians. The nonnegro group is widely distributed in many Mediterranean countries, particularly Greece, Italy, Sardinia and among certain Jewish groups. High incidences (up to $70 \%$ ) have been found in Jews from Kurdistan, Iraq and Persia, but low incidences among European Jews $(0.4 \%)$ and North African Jews. Further East G.6.P.D. deficiency has been recorded in India, China and the East Indies and there is a high incidence in Thailand. A number of fundamental differences exist between the negro and nonnegro groups. Electrophoretic studies on the G.6.P.D. enzyme itself have shown differences both in enzyme-deficient and normal individuals from these two racial groups. Furthermore the decrease in enzyme activity is much more marked in the non-negro group and this correlates with the more severe clinical effects in this group. The mode of inheritance is however the same in the two groups, being X-linked, affected males and homozygous females showing similar decreases in enzyme activity with heterozygous females having a less marked decrease.

Clinically a number of syndromes are associated with G.6.P.D. deficiency and these include drug-induced haemolysis, haemolysis caused by various foods, neonatal jaundice, haemolysis occurring during infections and a few cases which have been classified as hereditary non-spherocytic haemolytic anaemia. The commoner drugs to cause haemolysis include chloroquine and primaquine, certain sulphonamides such as sulphanilamide and sulphathiazole, probenecid and water-soluble analogues of vitamin K. A more complete list is given by Motulsky (1965) and detailed studies of the effects of various drugs have been done by a number of investigators including Tarlov, Bremmer, Carson and Alding (1962). The food involved is invariably fava beans, but other vegetables may have some clinical significance.

A knowledge of the geographical distribution and the precipitating factors of G.6.P.D. deficiency will enable the clinician to advise the patient on how to avoid many of its harmful effects. It is of great importance to explain to the patient the nature of this defect and to give him a list of precipitating factors.

\section{Case Report}

Mrs. C. A. was a Nigerian aged 28. Six days before admission she developed pain in the right side of the abdomen and some dysuria. The next day she became febrile, had several rigors and her urine darkened in colour. Three days before admission dysuria and abdominal pain persisted and she was seen by her general practitioner who thought she had a urinary infection and gave her furadantin. The day before admission she still had abdominal pain and remained pyrexial and had developed pain in both shoulders.

On admission her temperature was $99^{\circ} \mathrm{F}$., she was jaundiced, the liver was tender and the edge felt $3 \mathrm{~cm}$. below the costal margin. There was also tenderness in the right iliac fossa. A clinical diagnosis of infective hepatitis was made.

Investigations however, gave the following results: Hib. 8.8 g. $/ 100 \mathrm{ml}$., WBC 15,000 with a polymorph leucocytosis, the red cells showing slight polychromasia with a fair number of target cells. Bilirubin $5 \mathrm{mg} . / 100 \mathrm{ml}$. with a strong positive direct reaction. Thymol turbidity 2 units, zinc sulphate turbidity 3 units, alkaline phosphatase 150 units, SGPT 30 units. Plasma proteins normal. The urine showed many pus cells and cultures grew $E$. coli. Blood urea $70 \mathrm{mg} . / 100 \mathrm{ml}$.

Two days after admission her haemoglobin had fallen to $4.5 \mathrm{~g} . / 100 \mathrm{ml}$. with 35,000 white cells in $\mathrm{mm}$. mainly polymorphs and metamyelocytes. $3.5 \%$ reticulocytes and many nucleated red cells were present in the blood smear. Malarial parasites were not 
seen. Bone marrow examination revealed an erythroid hyperplasia with a normal iron content. By this time, the bilirubin and alkaline phosphatase had fallen to just within the normal range. Red cell G.6.P.D. activity gave results within the normal range.

She was given four pints of packed cells and courses of ampicillin and tetracycline. Two days after the transfusion the urea had fallen to $29 \mathrm{mg} . / 100 \mathrm{ml}$. Her haemoglobin gradually returned to normal, the reticulocytes reached a peak of $7 \%$ three days after the transfusion, and she rapidly became symptom free. Subsequent tests showed that she carried the hemoglobin $C$ trait. the red cell survival was normal. Cholecystogram normal. Repeat red cell G.6.P.D. estimation two months after the end of her illness, showed an enzyme level decreased to approximately $50 \%$ of the lower range of normal.

\section{Comment}

Mrs. C. A. is almost certainly heterozygous for G.6.P.D. deficiency, although no family studies were done. The original normal G.6.P.D. estimated which was obtained in the middle of the haemolytic episode emphasizes the need for repeated tests well after the haemolysis has subsided in order to detect milder degres of enzyme deficiency. A combination of urinary infection and treatment with a nitrofurantoin must have precipitated the haemolysis but the picture was complicated by a number of unusual features. The haemoglobin fell to a surprisingly low level. The enlarged and tender liver with an obstructive picture in the liver function tests implied that liver dysfunction was a least playing some part in the production of her jaundice. The appearances of her blood films with evidence of haemolysis together with target cells suggested initially that this was a crisis occuring in one of the homozygous haemoglobinopathies, but this was disproved by haemoglobin electrophoresis. This patient also emphasizes the need to estimate the G.6.P.D. when the reticulocytes have fallen to nearer normal levels after the haemolytic episode.

\section{Clinical Features}

The self-limiting haemolytic episode with jaundice, anaemia, reticulocytosis and perhaps haemoglobinuria is fairly easy to recognise and only certain aspects will be considered in greater detail. As already stated the clinical severity parallels the degree of enzyme deficiency and therefore non-negro racial groups will be the more markedly affected. Perhaps as an example of this, neonatal jaundice has not yet been shown to be related to G.6.P.D. deficiency in negro infants and neither has favism been definitely proved to occur in negroes, whereas in the non-negro groups they are important manifestations of G.6.P.D. deficiency. It is recognised that favism is often more severe than an episode of drug-induced haemolysis and it is commonly assumed that in favism some additional unidentified factor is involved.

In drug-induced haemolytic episodes, the disease for which the drug was given may merge with the haemolysis producing a complicated clinical picture. In addition, certain infections, both bacterial and viral, may themselves proz duce haemolysis in enzyme-deficient subject\$ The importance of the dose of the drug used has been emphasized in several studies. In: negro infants, Zinkham (1963) showed that $2.5 \mathrm{mg}$. of Synkavit will not cause any detectable haemolysis. Primaquine usually fails to produce any in G.6.P.D. deficient negroes in a dosage of less than $15 \mathrm{mg}$. per day, whereas $30 \mathrm{mg}$ daily will induce severe haemolysis. Nitro\% furantoin in normal doses (400 mg./day) has been shown to produce only slight effect, whereas double the normal dose will induce severe haemolysis. One must constantly bear in ming the differences between the two G.6.P.D. dee ficient groups, the negro and the non-negre, as results of investigations on one group do not necessarily apply to the other due to the differ ing degree of enzyme deficiency.

Finally among Northern Europeans an Japanese a very rare G.6.P.D. deficiency maф occur which results in a chronic haemolytic state which was originally classified in the Type I group of Hereditary Non-spherocytic Haemolytic Anaemias.

\section{Laboratory Tests}

Direct estimation of G.6.P.D. activity by ultiag violet spectrophotometry has been widely used but more simple procedures to detect this enzyme deficiency have been developed. Mosp of these procedures will diagnose accuratel affected males and homozygous females, bư will not detect differing percentages in an group of heterozygous females. In routine clinical practice a method should be used which will detect the majority of female heterozygotes

The Heinz body induction test is too in accurate. The glutathione stability test fails to detect adequate numbers of female heteros zygotes. However, Heinz bodies will occu? transiently during the haemolytic episode an $\$$ should be looked for in the reticulocyte prepara $₹$ tions. The two tests which have been mos widely used are the brilliant Cresyl Blue test of Motulsky and Campbell-Kraut (1961) ans. the methaemoglobin reduction test of Brewers Tarlov and Alving (1960). For routine hospitaT practice the methaemoglobin reduction test is probably the method of choice if direct estima tion of enzyme activity is not practicables With this test one should be able to deteos approximately $80 \%$ of female heterozygotesक Normal subjects will show 0 to $5 \%$ methaemo? globin whereas enzyme deficient subjects wilto range from 5 to $9.5 \%$ according to the severity? of the deficiency. 
We would like to thank the Physicians and Obstetricians at the Hospitals in the Group for their co-operation and permission to publish these cases, and Miss Celia Nelson for technical assistance and drawings.

\section{REFERENCES}

ApthorP, G. M., Measday, B., LehmanN, H. (1963): Pregnancy in Sickle Cell Anaemia, Lancet, i, 1346.

BetKe, K., Kleihauer, E. (1958): Fetaler und Bleibender Blutfarbstoff in Erythrozyzyten und Erythroblasten von menschlichen Feten und Neugeborenen, Blut, 4, 241.

Brewer, G. J., TARLOV, A. R., and Alving, A. S. (1960): Methaemoglobin Reduction Test, Bull. Wld. Hlth. Org., 22, 633.

BuchanaN, K. D., Kinlock, J. D., Hutchinson, H.E., Pinkerton, P. D., and CAssidy, P. (1963): Thalassaemia in Scots., J. clin. Path., 16, 6, 596.

CuRTIS, E. M. (1959): Pregnancy in Sickle Cell Anaemia, Sickle Cell-H.U.C. Disease and Variants Thereof, Amer. J. Obstet. Gynec., 77, 1312.

Eisenstein, M I., Posner, A. C., and Friedman, S. (1956): Sickle Cell Anaemia in Pregnancy, Amer. J. Obstet. Gynec., 72, 622.

Fessas, P. H., (1965): Forms of Thalassaemia. Abnormal Haemoglobins in Africa. p.71 C.I.O.M.S. Symposium, Oxford: Blackwells.

Fullerton, W. T., HendRICKSE, J.P. de V., WATSONWilliaMS, E. J. (1965): Haemoglobin S-C Disease in Pregnancy. Abnormal Haemoglobins in Africa, p.411, C.I.O.M.S. Symposium, Oxford: Blackwells.

Hall-CragGS, M., Marsen, P. D., Raper, A. B., LeNHANN, H., Beale, D. (1964): Homozygous Sickle Cell Anaemia arising from Two Different Haemoglobins S., Brit. med. J., ii, 87.

ItANO, H. A. and RobINSON, E. (1959): Properties and Inheritance of Haemoglobin by Asymmetric Recombination, Nature (Lond.)., 184, 1468.

MotUlsky, A. G. (1965): Theoretical and Clinical Problems of Glucose-6-Phosphate-Dehydrogenase Deficiency. Abnormal Haemoglobins in Africa, p.143., C.I.O.M.S. Symposium, Oxford: Blackwells. Motulsky, A. G., and Campbell Kraut, J. M. (1961): Population Genetics of Glucose-6-phosphate Dehydrogenase Deficiency of the Red Cell. Poceedings of the Conference on Genetic Polymorphisms and Geographic Variations in Disease p.159, New York and London:: Grune and Stratton.

Raper, A. B., Gammack, D. B., Huenns, E. R., and SHOOTER, E. M. (1960): Four Haemoglobins in one Individual, Brit. med. J., ii, 1257.

RoberTs, P. D., (1963): The Thalassaemia Trait in an English Family, J. clin. Path., 16, 6, 593.

Singer, K., Chernoff, A. I., SinGer, L. (1951): Studies on Abnormal Haemoglobins, I and II, Blood, 6, 413.

SMith, C. H., ERLandson, M. E., STERN, G., SchulmaN, I. (1960): The Role of Splenectomy in the Management of Thalassaemia, Blood, 15, 197.

Tarlov, A. R., Brewer, G. J., Carson, P. E., and Alving, A. S. (1962): Primaquine, SensitivityGlucose-6-phosphate Dehydrogenase Deficiency, an Inborn Error of Metabolism of Medical and Biological Significance, Arch. intern. med., 109, 209.

VANDERPITTE, J., and STIJNS, J. (1965): Haemoglobinopathies in the Congo (Leopoldville) and the Rwanda-Burundi. Abnormal Haemoglobins in Africa, p.321, C.I.O.M.S. Symposium, Oxford: Blackwells.

VAN OYE, E. (1960): Sur L'Association entre Ostéomyélite à Salmonella et L'Hémglobinopathie chez l'enfant Africain, Bull. Soc. Path. Exot., 53, 89.

Watson-Williams, E. J. (1965): Hereditary Persistence of Foetal Haemoglobin and Thalassaemia in Nigerians. Abnormal Haemoglobins in Africa, p.264, C.I.O.M.S. Symposium, Oxford: Blackwells. ZINKHAM, W. H. (1963): Peripheral Blood and Bilirubin, Values in Normal Full Term Primaquine Sensitive Negro Infants: Effect of Vitamin K.. Paediatrics, 31, 983. 
while Cumins contributes an interesting account of lipid changes in experimental and human demyelinations and some views on the pathogenesis. Depressive states are discussed by Pratt and Curzon. In the lecture on Genetic Mental Disorders, Slater concentrates on Wilson's disease, Schizophrenia and Huntington's chorea, while Richter gives a detailled account of the biochemical aspects of phenylketonuria, a comprehensive list of genetically determined metabolic disorders, and an interesting discussion on the relation of genes ito enzymes.

The editors are to be congratulated on this well produced book, which is a mine of useful information and should prove as popular as its predecessor.

\section{Depression}

A Cambridge Postgraduate Medical Course.

Edited by E. BERESFORD DAVIES, M.A., M.D., D.P.M. P. . 378. Cambridge: University Press. 1964. 90s.

This is a tape recording of a symposium held at Cambridge in 1959. It has been splendidly edited by Dr. Beresford Davies, who is the senior consultant psyohialtrist ito the United Cambridge Hospitals, so as to be eminently readable and never dull, despite its length.

One hundred and ninety participated in the symposium and among them were many of the most prominent British psychiatrists including the late Dr. W. Mayer Gross, the late Professor A. Kennedy, Sir Aubrey Lewis, Professor E. Stengel and Dr. W. Sargant, as well as a few representatives from other countries. The symposium was divided into four sections-clinical, psychological, neuropharmacological and therapeutic and each section comprised three or four main papers followed by the detailed proceedings of three to five discussion groups. Every aspect of depression is covered and there can be no doubt that the book will be of value to all psychiatric consultants and trainees. Sir Aubrey Lewis' general review of depressive conditions and Dr. Sargant's paper on the physical treatments of depression deserve especial mention. One cannot help feeling, however, that had all the discussion group proceedings been omitted and the book reduced to the main papers it would have commanded a very wide circulation. As it is its price is so high and its size is so formidable that is will not commend itself to general physicians or general practitioners. A further difficulty is that publication was not possible unitil five years after the symposium itook place and during that five years a host of new antidepressant drugs have become available.

Elastolysis and Ageing

David A. Hall. Pp. xiii +160 illustrated. Spring- field Illinois: Charles C. Thomas, 1964. Price $\$ 6.75$.

This monograph in the American Lecture Series is written by the leader of the elastic tissue research group at Leeds University.

In it Dr. Hall summarises what is known of the structure and biochemistry of elastic tissue and its changes with age.

Elastin, unlike collagen, has no characteristic X-ray diffraction patterns or electron microscopic appearances. It cannot therefore be studied by physical means and chemical methods are essential. The principal technique has been the study of elastolysis, the name given to the new breakdown of elastin by the pancreatic enzymes, elastase and elastolipoproteinase.

Dr. Hall first reviews the properties of elastin itself. He then discusses the enzymes causing elastolysis and the substances which inhibit their action in vitro and in vivo. In a final chapter he discusses elastolysis in relation to the process of ageing and atherosolerosis. The susceptability to elastolysis of elastic tissue in the wall of the aorta is minimal in the young but increases steadily with age. Dr. Hall postulates that this may be due to the loss with advancing years of inhibiting substances which prevent elastolysis in youth. Elastin is a lipoprotein and Dr. Hall suggests that separation of the lipid fraction may underlie the formation of the atheroscerostic plaque.

Dr. Hall gives nearly 300 references including 50 to work by himself or his colleagues but much of the book deals with hypothesis and there is evidently a need for much more research before this complex subject can be crystallised for the general medical reader. At present it is a field for specialists who will undoubtedly be stimulated by Dr. Hall's challenging monograph.

\section{Relations of Development and Ageing}

Edited by JAmes E. BIRREN, Ph.D. Pp. v+256 illustrated. Springfield, Illinois: Charles C. Thomas. 1964. $\$ 9.50$.

This book present the proceedings of a conference of the Gerontological Society of America held at Miami Beach, Florida, in 1964.

The contributors are mostly psychologists and sociologists, though there are a few interesting contributions in other fields particularly one on age changes in bones by Garn, Rohanm and Nolan.

Much of the psychology is very academic and will prove heavy going for the medical reader, but it is interesting to see the way in which research in gerontology is looking further and further back in an attempt to see the processes of ageing in relation to the whole span of human life. The child is after all father to the man.

\section{ERRATUM :}

'Haemoglobinopathies in Immigrant Families' by M. J. Beard and A. Gordon Signy. Postgrad. med. J. (1965), 41, 624-633.

Section headed Laboratory Tests, p. 632:

1. lines 6 and 7 should read "and will detect differing percentages ..." instead of "but will not detect ...".

2. bottom line should read "will range from 5 to $95 \%$ according to the severity of the deficiency." instead of "5 to $9.5 \%$...". 